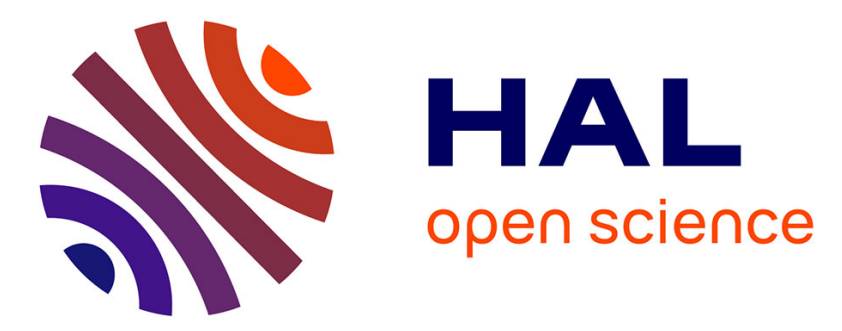

\title{
Poly (N-Vinyl Carbazole) and Carbon Nanotubes based Composites and their Application to Rechargeable Lithium Batteries
}

\author{
M. Baibarac, M. Lira-Cantú, J. Oró Sol, I. Baltog, N. Casañ-Pastor, P. \\ Gomez-Romero
}

\section{To cite this version:}

M. Baibarac, M. Lira-Cantú, J. Oró Sol, I. Baltog, N. Casañ-Pastor, et al.. Poly (N-Vinyl Carbazole) and Carbon Nanotubes based Composites and their Application to Rechargeable Lithium Batteries. Composites Science and Technology, 2007, 67 (11-12), pp.2556. 10.1016/j.compscitech.2006.12.008 . hal-00498979

\section{HAL Id: hal-00498979 https://hal.science/hal-00498979}

Submitted on 9 Jul 2010

HAL is a multi-disciplinary open access archive for the deposit and dissemination of scientific research documents, whether they are published or not. The documents may come from teaching and research institutions in France or abroad, or from public or private research centers.
L'archive ouverte pluridisciplinaire HAL, est destinée au dépôt et à la diffusion de documents scientifiques de niveau recherche, publiés ou non, émanant des établissements d'enseignement et de recherche français ou étrangers, des laboratoires publics ou privés. 


\section{Accepted Manuscript}

Poly (N-Vinyl Carbazole) and Carbon Nanotubes based Composites and their Application to Rechargeable Lithium Batteries

M. Baibarac, M. Lira-Cantú, J. Oró Sol, I. Baltog, N. Casañ-Pastor, P. GomezRomero

PII:

S0266-3538(07)00003-6

DOI:

10.1016/j.compscitech.2006.12.008

Reference:

CSTE 3555

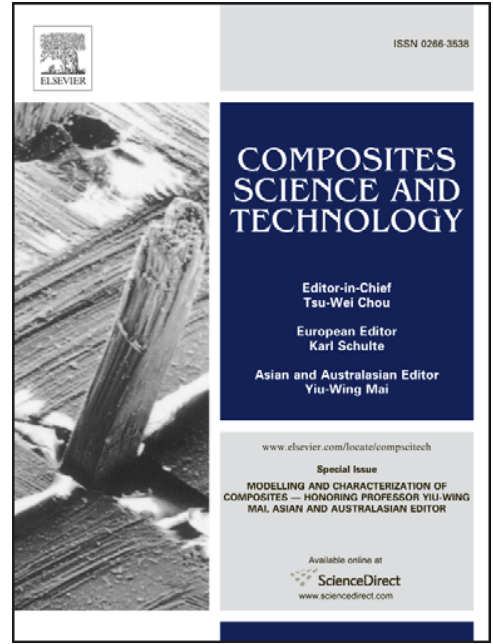

To appear in:

Composites Science and Technology

Received Date:

15 February 2006

Revised Date:

15 December 2006

Accepted Date:

16 December 2006

Please cite this article as: Baibarac, M., Lira-Cantú, M., Oró Sol, J., Baltog, I., Casañ-Pastor, N., Gomez-Romero, P., Poly (N-Vinyl Carbazole) and Carbon Nanotubes based Composites and their Application to Rechargeable Lithium Batteries, Composites Science and Technology (2007), doi: 10.1016/j.compscitech.2006.12.008

This is a PDF file of an unedited manuscript that has been accepted for publication. As a service to our customers we are providing this early version of the manuscript. The manuscript will undergo copyediting, typesetting, and review of the resulting proof before it is published in its final form. Please note that during the production process errors may be discovered which could affect the content, and all legal disclaimers that apply to the journal pertain. 
Poly (N-Vinyl Carbazole) and Carbon Nanotubes based Composites and their Application to Rechargeable Lithium Batteries

M. Baibarac, ${ }^{1 *}$ M. Lira-Cantú, ${ }^{1}$ J. Oró Sol, ${ }^{1}$ I. Baltog ${ }^{2}$

N. Casañ-Pastor ${ }^{1}$ and P. Gomez-Romero ${ }^{1 *}$

${ }^{1}$ Institut de Ciència de Materials de Barcelona (CSIC),

Campus de la UAB, 08193 Bellaterra (Barcelona), Spain

${ }^{2}$ National Institute of Materials Physics, Lab. Optics and Spectroscopy, Bucarest, P.O.Box MG-7, R-77125, Romania

\section{Corresponding author:}

Dr. M. Baibarac ${ }^{\dagger}$ and Dr. P. Gomez-Romero

Fax: +34 935805729

E-mail: mbaibarac@icmab.es

†Permanent address: Nacional Institute of Materials Physics, Lab. Optics and Spectroscopy, Bucarest, P.O.Box MG-7, R-77125, Romania, e-mail: barac@infim.ro 


\begin{abstract}
In order to the preparation of poly (N-vinyl carbazole) (PVK) and carbon nanotubes (CNs) based composites, electrochemical polymerisation of $\mathrm{N}$-vinyl carbazole (NVK) was studied by cyclic voltammetry (CV) in $\mathrm{LiClO}_{4}$ /acetonitrile solutions. Cyclic voltammograms recorded on blank Pt electrode and those obtained when single or multi-walled carbon nanotubes (SWNTs or MWNTs) films were previously deposited onto the Pt electrode show a down-shift of the VK reduction peak potential in the latter case. The influence of monomer concentration and supporting electrolyte on the polymerisation conditions and electrochemical properties of these composite materials were also investigated. Morphologic aspects as well as the photoluminescence properties of PVK/CNs composite were also investigated. A covalent functionalization of carbon nanotubes with PVK is suggested on the basis of infrared (IR) spectroscopic studies. Using PVK/CNs composite as positive electrode and an electrolytic solution containing $\mathrm{LiPF}_{6}$, higher specific discharge capacity of the rechargeable lithium cells, $\sim 45$ and $115 \mathrm{~mA} \mathrm{~h} \mathrm{~g}^{-1}$, are reported for PVK functionalized SWNTs and MWNTs, respectively.
\end{abstract}

Keywords: A. Polymer-matrix composites (PMCs); A. Nanostructures; D. Transmission electron microscopy (TEM); D. Infrared (IR) spectroscopy. 


\section{Introduction}

As a result of the first report concerning the preparation of carbon nanotubes (CNs),[1] many efforts have been made to combine CNs and polymers to produce functional composite materials with superior properties.[2,3] Apart from possible improvements in the mechanical and electrical properties of polymers, the formation of $\mathrm{CNs}$ /polymer composites has been, and still is, explored as a promising approach for an effective incorporation of CNs into practical devices.[4-8] The combination of the unique properties of CNs with conducting organic polymers (for example: polyaniline, polypyrrole, polythiophene, poly (3,4-ethylenedioxy thiophene), poly ( $\mathrm{p}$-phenylene vinylene) and poly (m-phenylene vinylene-co-2,5-dioctoxy-p-phenylene)) makes of these materials interesting multifunctional systems with great potential in many applications such as supercapacitors, sensors, advanced transistors, high-resolution printable conductor, electromagnetic absorbers, photovoltaic cells and photodiodes and, last but not least, optical limiting devices.[9] As a result of the optical limiting performance and the good photoconductivity, special attention has been give to the carbon nanotubes functionalized with poly (N-vinyl carbazole) (PVK/CNs).[10-12] For PVK/CNs composites, two synthesis methods have been reported so far: i) direct mixing of the polymer with nanotubes and ii) chemical polymerisation of monomer in the presence of carbon nanoparticles.[10,13] In the present work, using electrochemical polymerisation of NVK on CNs films, new applications of PVK/CNs composites in the energy storage field are revealed. The influence of monomer concentration and supporting electrolyte on the polymerisation conditions of NVK on films of single or multi-walled carbon nanotubes (SWNTs or MWNTs) were also studied. When preparing a composite, it is essential to determine the type of interaction between the 
two constituents. To this end, TEM, IR and photoluminescence investigations are also presented.

According to the Hirsh's paper, the main possibilities to functionalize CNs reported so far are: i) generation and functionalization of defect sites at the tube ends and side walls by oxidation and subsequent conversion into derivatives; ii) covalent functionalization of side wall by addition reactions and subsequent nucleophilic substitution; iii) non-covalent exohedral functionalization with surfactant-type molecules and iv) endohedral functionalization with $\mathrm{C}_{60}$. [14] We note that, in the case of conducting organic polymer/carbon nanotubes composites (COP/CNs), it has been suggested that either the polymer functionalizes the CNs or the COPs are doped with CNs, i.e. a charge transfer occurs between the two constituents.[9] Consequently, two kinds of composites can be obtained: polymer-functionalized CNs and polymer doped with CNs.

\section{Experimental Section}

Using cyclic voltammetry (CV), the electrochemical polymerization of VK was performed in the potential range $(-0.8 ; 1.8) \mathrm{V}$ vs. $\mathrm{Ag} / \mathrm{AgCl}$ in a conventional threeelectrode one-compartment cell. To obtain PVK and PVK-functionalized CNs, the working electrode was $\mathrm{Pt}$ or a CNs film deposited on a $1 \mathrm{~cm}^{2} \mathrm{Pt}$ plate. The counter electrode consisted of a spiral Pt wire. The potential of the working electrode was

measured by reference to $\mathrm{Ag} / \mathrm{Ag}^{+}$. The polymerisation solution consisted of $610^{-3} \mathrm{M}$ VK and $10^{-1} \mathrm{M} \mathrm{LiClO}_{4}$ in acetonitrile. Acetonitrile (AN), $\mathrm{LiClO}_{4}$, single-walled carbon nanotubes (SWNTs), multi-walled carbon nanotubes (MWNTs) and N-vinyl carbazole (NVK) were purchased from Aldrich. 
The electrochemical polymerization was performed using a potentiostat/ galvanostat from Princeton Applied Research (PAR), model 273A.

TEM images of PVK/SWNTs and PVK/MWNTs composites are recorded with a JEOL 1210 electron microscope operating at $120 \mathrm{kV}$.

Photoluminescence (PL) spectra at room temperature were obtained under 265 $\mathrm{nm}$ light excitation coming from a $150 \mathrm{~W}$ high pressure xenon lamp in a right angle geometry using a computer-controlled emission spectrometer consisting from a SPEX double monochromator equipped with a cooled EMI photomultiplier and a photon counting system.

Attenuated total reflection infrared (ATR-IR) spectra, in the range $400-4000$ $\mathrm{cm}^{-1}$ with a $4 \mathrm{~cm}^{-1}$ resolution, were obtained using a Perkin-Elmer model 683 instrument.

Charge/discharge tests were carried out using a multichannel charge-discharge galvanostatic analyser (Arbin Instruments, College Station, USA). To fabricate the positive electrode (cathode), we used PVK functionalised - MWNTs and SWNTs $(80 \%$ wt., as activ material), poly(vinylidene fluoride) (PVDF 5\% wt., as binder), super-P carbon (15\% wt.), dibuthyl phthalate (DBP, 2 drops) and $1 \mathrm{ml}$ acetone, which were mixed and stirred for $12 \mathrm{~h}$ to yield a homogeneous paste. The paste was tape-cast onto a glass surface and the acetone allowed to evaporate. After peeling-off the resulting film, it was washed with diethyl ether in order to remove DBP. Lithium foil of $0.38 \mathrm{~mm}$ thickness and area of $2.03 \mathrm{~cm}^{2}$ was used as the negative electrode (anode). The electrolyte used was a $1 \mathrm{M}$ solution of $\mathrm{LiPF}_{6}$ in a 50:50 mixture of ethylene carbonate and dimethyl carbonate (v/v). The cell assembly was carried out under purified argon atmosphere in a glove box. Electrochemical testing of the cell was performed using 
constant-current cycles. The current density was $10 \mathrm{~mA} \mathrm{~g}{ }^{-1}$. The cells were cycled between 1 and $3.5 \mathrm{~V}$.

\section{Results and Discussion}

As it has been reported, electrolysis of NVK in organic solvents as acetonitrile and propylene carbonate results in the formation of a white-colored non-conducting PVK and a green-colored conducting PVK.[15] The non-conducting PVK precipitates in electrolyte solution and the conducting PVK is deposited onto the working electrode surface. Figure 1 shows cyclic voltammograms obtained on a blank Pt electrode and on a Pt electrode coated with a SWNTs film, using a solution of $\mathrm{VK}$ in $\mathrm{LiClO}_{4} / \mathrm{CH}_{3} \mathrm{CN}$. An irreversible oxidation peak at ca. $1.4 \mathrm{~V}$ is detected on the anodic scan of Figure 1a. This corresponds to the formation of the NVK radical cation which entails, on the reverse scan, a reduction wave at ca. $0.8 \mathrm{~V}$. The suggested mechanism for the anodic oxidation of NVK consists in the formation of a carbazyl radical cation, which on subsequent dimerization of the 3,6 position gives 3, 3'-dicarbazyl, a crosslinked material with electrical-conducting behaviour. [15] In these circumstances, the non-conducting PVK produced by the electrolysis of the monomer can be oxidized to yield the conducting green polymer. The gradual increase in the intensity of waves with repeated sweeps indicates that the reaction product is gradually deposited on the surface of the $\mathrm{Pt}$ electrode. As can be seen in Figure 1b, a great difference is observed in shape of the cyclic voltammograms recorded on the Pt electrode coated with a SWNTs film. A down-shift of the reduction potential peak of NVK was observed when films of single or multi-walled carbon nanotubes (SWNTs or MWNTs) were previously deposited onto the Pt electrode. In both cases, i.e. using the blank Pt electrode and coated with a CNs 
film, an oxidation reaction starts to develop in the potential range $(0.75 ; 1.8) \mathrm{V}$ vs. $\mathrm{Ag} / \mathrm{Ag}^{+}$during the anodic scan. Regardless of the number of cycles carried out on the SWNTs film deposited on Pt electrode, no anodic peak is observed for the cathodic maximum found around $0.4 \mathrm{~V}$ (Figure $1 \mathrm{~b}$ ). Similar behaviour is obtained when the Pt electrode is coated with a MWNTs film. The presumption that the cathodic peak localized at $0.4 \mathrm{~V}$ (Figure $1 \mathrm{~b}$ ) can be attributed to the $\mathrm{CNs} / \mathrm{LiClO}_{4}$ redox system is in total disagreement with Ref. 16, which used as evidence the fact that in the presence of $10^{-1} \mathrm{M} \mathrm{LiClO}_{4} / \mathrm{CH}_{3} \mathrm{CN}$ solution, the cyclic voltammogram of $\mathrm{CNs}$ shows the welldefined reduction and oxidation responses at ca. -0.6 and $-0.2 \mathrm{~V}$ vs. $\mathrm{Ag} / \mathrm{Ag}^{+}$, respectively. In this context, at a first sight, the electrochemical process which takes place at the interface the $\mathrm{CNs}$ film immersed in the $\mathrm{VK} / \mathrm{LiClO}{ }_{4} / \mathrm{CH}_{3} \mathrm{CN}$ solution is difficult to understand. Such a down-shift of the cathodic peak in comparison with the polymer synthesized without $\mathrm{CNs}$ has been reported also for polypyrrole /carbon nanotubes composites, SWNTs having a doping role.[19]

It is well known that carbon nanotubes are amphoteric, i.e. they can be doped with either electron donors $(\mathrm{K}, \mathrm{Rb})$ or electron acceptors $\left(\mathrm{Br}_{2}\right) .[17,18]$ Taking into account that in the presence of electrons donor molecules, for example dimethylacetamide (DMA) or dimethylformamide (DMF), the anodic oxidation of NVK is delayed or just inhibited, respectively [15] the question may be asked: Is the electropolymerization of NVK inhibited when a Pt electrode covered with a carbon nanotubes film is used as working electrode?

Trying to find an answer to the above question, in the following, we show TEM micrographs of both the starting materials (SWNTs and MWNTs) and of the composite obtained after a series of 25 cyclic voltammograms in $\mathrm{CH}_{3} \mathrm{CN}+\mathrm{LiClO}_{4}\left(10^{-1} \mathrm{M}\right)+$ 
NVK (6 $\left.10^{-3} \mathrm{M}\right)$ solution (Figure 2) as well as photoluminescence spectra of PVK and PVK functionalized CNs (Figure 3). In this paper, we use CNs lots with the following characteristics: i) SWNTs - diameter between 1.2-1.5 nm and length of 2-5 $\mu \mathrm{m}$ and ii) MWNTs - outer diameter is of 10-20 nm, inner diameter 5-10 nm and length 0.5-200 $\mu \mathrm{m}$. A careful analysis of TEM pictures clearly discloses that a deposition of PVK on the SWNTs and MWNTs films has occurred. Under the same experimental conditions, the most uniformly deposition of PVK is observed in the case MWNTs. We believe that this fact is the result of regions with "bamboo-like" structures that lead to a high number of edge-plane defect sites along the tube surface. Convincing proof for the deposition and interaction of PVK with CNs is gathered by PL studies summarized in Figure 3. As in the PL studies carried out by S. Balaei et al.[20] the ex-situ PL spectrum of PVK film, electrochemical deposited on Pt electrode, is characterized by an emission band with the maximum at $415 \mathrm{~nm}$ (Figure 3, curve 4), which is assigned to the low-energy excimer. A similar PL band is observed also when cyclic voltammetry is applied on SWNTs film immersed in the solution of $\mathrm{VK} / \mathrm{LiClO}_{4} / \mathrm{CH}_{3} \mathrm{CN}$. A gradual shift of the PVK PL band maximum, from 442 to $415 \mathrm{~nm}$, is observed as an increase of the cyclic number recorded on the SWNT film takes place. Similarly to other composites systems, (for example poly(p-phenylene vinylene)/MWNTs, [8] aniline/SWNTs [21] and aromatic hydrocarbons with isolated or condensed phenyl rings/SWNTs [22]) when the electropolymerization of VK takes place on the SWNTs film the appearance of a vibronic structure in the high energy side of the emission spectrum of PVK (at ca. 483 nm, namely $2.57 \mathrm{eV}$ ) is observed. According to curves 1, 2 and 3 from Figure 3, a decrease in the intensity of the vibronic structure at $2.57 \mathrm{eV}$ is observed after achievement of 20, 50 and 100 cyclic voltammograms, respectively, on the SWNTs film 
deposited on Pt electrode (immersed into a $\mathrm{NVK} / \mathrm{LiClO}_{4} / \mathrm{CH}_{3} \mathrm{CN}$ solution). At first sight the appearance of the vibronic structure may be explained in two ways, firstly referring to the appearance of additional defect sites in the PVK structure where the excitation energy is trapped [23] and secondly considering that the emission has to be correlated with dopant role of CNs. Taking into account that singlet-triplet intersystem crossing is relatively inefficient in PVK, [24] we think that the vibronic structure at 2.57 $\mathrm{eV}$ originates in singlet states and the straightening on the high energy side of the vibronic structure represent the signature of functionalization of the SWNTs with PVK molecules that are bound covalently on the nanotube side-wall. Within this frame, with PVK molecule playing the role of luminescence site in the PVK/CNs composite, one can suppose that in the generation of PL emission there are two contributions: one that is due to intramolecular transitions (pure electronic and vibronic) which takes place in the PVK molecule and another that reflects coupling of these transitions to the intermolecular vibrations (phonons) field of the environment resulting from the interactions between nanotubes and PVK molecules. The former contribution gives rise to Lorentzian-shaped zero-phonon lines, with widths determined by the de-phasing times of the excited state while the latter lead to the changes of the phonon spectrum.

Generally, the smaller coupling of the phonon field to the electronic transition enhances the $S_{1} \rightarrow S_{0} / 0 \rightarrow 1$ transition in both absorption and fluorescence at the expense of the $S_{1} \rightarrow S_{0} / 0 \rightarrow 0$. We assign the enhancement of the vibronic structure in the blue side of PL spectrum to a strong coupling of the CNs phonons with the electronic transition of the type $S_{1} \rightarrow S_{0} / 0 \rightarrow 0$. Such a coupling is favoured by the close binding of PVK molecules to the nanotube side-wall. We use here the notation $S_{1} \rightarrow S_{0} / n \rightarrow m$ that 
denotes a transition from the first singlet excited state $S_{1}$ to the ground state $S_{0}$ and between the $n$th vibration level of $S_{1}$ to $m$ th vibration level of $S_{0}$.

Figure 4 displays the attenuated total reflection infrared (ATR-IR) spectra of PVK deposited on i) a bare Au electrode and ii) a Au electrode coated with a SWNTs film. The main absorption bands of PVK situated at ca. 722, 744, 1220, 1320 and 1450 $\mathrm{cm}^{-1}$ are attributed to the following vibrations: ring deformation of substituted aromatic structure, $\mathrm{CH}_{2}$ rocking vibration due to tail to tail addition, $\mathrm{C}-\mathrm{H}$ in plane deformation of aromatic ring, $\mathrm{C}-\mathrm{H}$ in-plane deformation of vinylidene group and ring vibration of $\mathrm{VK}$ moiety, respectively.[25]

A new band at $1258 \mathrm{~cm}^{-1}$ can be seen in Figure 5, for the PVK/SWTNs composite obtained after the achievement of 50 cyclic voltammograms carry out on the SWNTs film immersed in the $\mathrm{VK} / \mathrm{LiClO}_{4} / \mathrm{CH}_{3} \mathrm{CN}$ solution. The new band can be associated to the $\mathrm{C}-\mathrm{C}$ stretching vibration in benzene ring deformation, [26] their appearance being the result of the formation of the new $\mathrm{C}-\mathrm{C}$ bonds between the aromatic ring of SWNTs and vinylidene group of NVK molecules. In our opinion, this band can be considered as the signature of the interaction between SWNTs and NVK. The modification of the intensity ratio between the IR bands at ca. 723 and $744 \mathrm{~cm}^{-1}$ indicates a partial change of the addition mechanism of the monomer as well as the presence of some steric hindrance effects. We think that a result of the electrochemical process which takes place at the interface $\mathrm{SWNTs} / \mathrm{VK}+\mathrm{LiClO}_{4}+\mathrm{CH}_{3} \mathrm{CN}$ is the formation of composites with the repeating units in both a tail-to-tail and head-to-tail addition. We note that the mechanism of the PVK electrosynthesis is well known.[15] However, in order to explain the interactions proposed above between SWNTs/VK, in Scheme 1 a multistage mechanism is proposed for the electropolymerization reaction of 
NVK in the presence of SWNTs. This involves the formation of a charge-transfer complex (CTC), that is similar to those recently reported for the case of aniline reacting with CNs, [27] originating from a VK radical cation and a SWNTs radical anion. After the second chemical stage, all reactions for the conversion of the non-conducting PVKfunctionalized SWNTs composite into its conducting form take place in the same way as those reported in literature for PVK.[28] The chemical equations of the two composites are presented in Scheme 2 (where by $\mathrm{A}^{-}$is noted $\mathrm{ClO}_{4}{ }^{-}$and $\mathrm{SWNTs}^{-}$).

The mechanism, proposed above supports the following experimental facts: i) the presence of a head-to-tail addition of monomer, ii) the perturbations of the benzene ring of $\mathrm{CNs}$ as a result of the functionalization with polymer as well as steric hindrance effects and iii) existence of the defect sites in PVK structure, the consequence of the CTC formation depicted in stage 1. Summarizing these results, in our opinion the ATRIR and PL spectra as well as TEM pictures, are irrefutable proofs that a functionalization of the CNs films with PVK took place.

Because one the goals of this paper is to demonstrate that the PVKfunctionalized $\mathrm{CNs}$ can be used as electrodes in rechargeable lithium batteries, a detailed knowledge of electrochemical parameters of this composite synthesis is necessary. In what follows, a very short review of the influence of monomer and support electrolyte concentration on the electrochemical process is presented in Figure 5. Knowing that the reaction rate is proportional to monomer concentration, in Figure 5a one observe large current responses when VK concentration is increased. Other variations induced in the cyclic voltammogram shape consist of the gradual growth of the current density of the cathodic maximum from $15.4 \mathrm{~mA} \mathrm{~cm}^{-2}$ to 25.7 and $31.8 \mathrm{~mA}$ $\mathrm{cm}^{-2}$, a change that is accompanied by a progressive down-shift of the cathodic peak 
potential from $0.36 \mathrm{~V}$ to 0.18 and $0.09 \mathrm{~V}$ vs. $\mathrm{Ag} / \mathrm{Ag}^{+}$, when $\mathrm{VK}$ concentrations of $310^{-3}$, $610^{-3}$ and $2.410^{-2} \mathrm{M}$, respectively are used. Maintaining constant VK concentration and using different $\mathrm{LiClO}_{4}$ concentration, higher and higher, large current responses are obtained (Figure 5b).

These large current density can be correlated with the increase in the electrolyte conductivity. Increasing the $\mathrm{LiClO}_{4}$ concentration induces in the cyclic voltammogram shape an up-shift of cathodic peak potential from -0.1 until to $0.58 \mathrm{~V}$ vs. $\mathrm{Ag} / \mathrm{Ag}^{+}$. Taking into account this experimental result and returning to Figure $1 \mathrm{~b}$, we conclude that the down-shift of the cathodic peak potential, mentioned above, is due to the dopage of PVK - covalent functionlized SWNTs with both $\mathrm{LiClO}_{4}{ }^{-}$ions and SWNTs radical anions. We reach this conclusion because it is difficult to understand how, during the first 100 cyclic voltammograms, the $\mathrm{LiClO}_{4}$ concentration can decrease of ca. 5 times.

We note that much effort has been carried out for the optimisation of the performances of polycarbazole batteries.[29,30] An example is the study reported in aqueous electrolytes using a cell of the type $\mathrm{Zn} / \mathrm{ZnClO}_{4} /$ polycarbazole, battery which were characterized by a specific capacity of $30 \mathrm{~A} \mathrm{~h} \mathrm{Kg}^{-1}$ and an energy density of $46 \mathrm{~W}$ $\mathrm{h} \mathrm{Kg}^{-1}$.[29] These characteristics were reported as being superior to the features of the cell of the type $\mathrm{Li} / \mathrm{LiClO}_{4}-\mathrm{PC} / \mathrm{PVK}$.[29] Our preliminary studies shown an improvement of the specific capacity of the rechargeable lithium battery when a cathodic electrode of the type PVK-functionalized SWNTs or PVK-functionalized MWNTs is used. Different characteristics are found for the two composites, as shown by an analysis of the voltage profile and incremental capacity curves (Figure 6). For the two composites a significant decrease of capacity during the first 10 charge-discharge cycles is observed. Afterwards, 
the increase in the number of charge-discharge cycles leads to a smaller decrease of the cell capacity in the case of the PVK-functionalized SWNTs active material, while for PVK-functionalized MWNTs an increase of the capacity takes place. We believe that this experimental fact can probably be related to a more pronounced degradation of the PVK-functionalized SWNTs in the comparison with composites based on PVK and MWNTs. During the 20th charge-discharge cycle the discharge capacities of ca. 45 and $115 \mathrm{~mA} \mathrm{~h} \mathrm{~g}^{-1}$ were recorded for PVK-functionalized single and multi walled carbon nanotubes, respectively. This result indicates that the electrochemical performance of a PVK battery is much improved when a PVK/CNs composite is used as active material because of the apparent synergism between the host polymeric matrix and guest nanoparticles, as detected in other hybrid systems.[31] The effect of the composites on the lithium site potential is shown in Figure 6. Analyzing the incremental curves of the two composites (inserts from Figure 6) electrochemical activity associated with $\mathrm{Li}$ insertion in the range $2.5-3 \mathrm{~V}$ (during discharge) is detected in both cases. On the other hand, a striking difference between PVK/SWNTs and PVK/MWNTs composites is observed in the range $1.5-2.5 \mathrm{~V}$, the latter showing a two stages intercalation process which increases in the intensities with the number of cycles. It is also interesting to note a change in the relative intensities of the two peaks for the PVK/MWNT composite. These changes are especially apparent for the two stages of discharge (at 1.52 and 1.86 V) which go from a ratio of $1.4: 1\left(10^{\text {th }}\right.$ cycle $)$ to $1: 1.7\left(20^{\text {th }}\right.$ cycle $)$. Understanding this particular behaviour will involve further research. However, the data presented here are more than sufficient to show that: i) these hybrid nanocomposites perform better in rechargeable $\mathrm{Li}$ batteries than the PVK materials alone and ii) the PVK/MWNTs 
composite presents a larger (and growing) charge capacity storage as compared with the PVK functionalised SWNTs.

\section{Conclusion}

This paper reports new results concerning the electrochemical synthesis of PVKfunctionalized CNs composites and the improvement upon the PVK performance as active material in rechargeable lithium batteries. Correlated studies of the cyclic voltammetry, ATR-IR spectroscopy, photoluminescence and TEM confirm the functionalization of $\mathrm{CNs}$ with PVK. A reaction mechanism is proposed. An improvement of the specific capacity of PVK in rechargeable Li cells is reported by using carbon nanotubes at electrosynthesis of conducting organic polymer.

\section{Acknowledgment}

A post-doctoral fellowship to $\mathrm{MB}$ by the Spanish Ministry of Science is gratefully acknowledged. Partial funding from the Spanish Ministry of Science and Technology (grant no. MAT 2002-04529-C03) is also acknowledged.

\section{References}

[1] S. Iijima, Helical microtubules of graphitic carbon. Nature (London, U. K.) 1991; 354: 56.

[2] P. M. Ajayan, O. Stephan, C. Colliex, D. Trauth, Aligned carbon nanotube formed by cutting a polymer resin-nanotube composite. Science 1994; 265 : 1212-1214; L. Dai, A.W. H. Mau, Controlled Synthesis and Modification of 
Carbon Nanotubes and $\mathrm{C}_{60}$ : Carbon Nanostructures for Advanced Polymeric Composite Materials. Adv. Mater. 2001; 13: 899-913.

[3] R. H. Baughman, A. A. Zakhidov, W. A. Heer, Carbon nanotubes - the route toward applications. Science 2002; 197: 787-792.

[4] L. Dai, Advanced syntheses and microfabrications of conjugated polymers, $\mathrm{C}_{60^{-}}$ containing polymers and carbon nanotubes for optoelectronic applications. Polym. Adv. Technol. 1999; 10: 357-420.

[5] G. Z. Chen, M. S. P. Shaffer, D. Coleby, G. Dioxan, W. Zhou, D. J. Fray, A. H. Windle, Carbon Nanotube and Polypyrrole Composites: Coating and Doping. Adv. Mater. 2000; 12: 522-526.

[6] Y. Saito, S. Uemura, K. Hamaguchi, Cathode Ray Tube Lighting Elements with Carbon Nanotube Field Emitters. Jpn. J. Appl. Phys. 1998; 37: L346-L348.

[7] S. A. Curran, P. M. Ajayan, W. J. Blau, D. L. Carroll, J. N. Coleman, A. B. Dalton, A. P. Davey, A. Drury, B. McCarthy, S. Maier, A. Strevens, A Composite from Poly( $m$-phenylenevinylene-co-2,5-dioctoxy- $p$-phenylene vinylene) and Carbon Nanotubes: A Novel Material for Molecular Optoelectronics. Adv. Mater. 1998; 10: 1091-1093.

[8] H. Ago, K. Petritch, M. S. P. Shaffer, A. H. Windle, R. H. Friend, Composites of Carbon Nanotubes and Conjugated Polymers for Photovoltaic Devices. Adv. Mater. 1999; 11: 1281-1285.

[9] M. Baibarac, P. Gomez-Romero, Nanocomposites Based on Conducting Polymers and Carbon Nanotubes: From Fancy Materials to Functional Applications. J. Nanosci. Nanotechnol. 2006; 6: 289-302. 
[10] W. Wu, J. Li, L. Liu, L. Yanga, Z. X. Guo, L. Dai, D. Zhu, The photoconductivity of PVK-carbon nanotube blends. Chem. Phys. Lett. 2002; 364: 196-199.

[11] C. Li, C. Liu, F. Li, Q. Gong, Optical limiting performance of two soluble multi-walled carbon nanotubes. Chem. Phys. Lett. 2003; 380: 201-205.

[12] W. Wu, S. Zhang, Y. Li, J. Li, L. Liu, Y. Qin, Z. X. Guo, L. Dai, C. Ye, D. Zhu, PVK-Modified Single-Walled Carbon Nanotubes with Effective Photoinduced Electron Transfer. Macromolecules 2003; 36: 6286-6288.

[13] W. Wang, Y. Lin, Y. P. Sun, Poly( $N$-vinyl carbazole)-functionalized singlewalled carbon nanotubes: Synthesis, characterization, and nanocomposite thin films. Polymer 2005; 46: 8634-8640.

[14] A. Hirsch, Functionalization of Single-Walled Carbon Nanotubes. Angew. Chem. Ind. Ed. 2002; 41: 1853-1859.

[15] J. E. Dubois, A. Desbene-Monvernay, P. C. Lacaze, Polaromicrotribometric (PMT) and IR, ESCA, EPR spectroscopic study of colored radical films formed by the electrochemical oxidation of carbazoles : Part II. $N$-vinylcarbazole. J. Electroanal. Chem. 1982; 132: 177-190.

[16] J. N. Barisci, G. G. Wallace, R. H. Baughman, Electrochemical Characterization of Single-Walled Carbon Nanotube Electrodes. J. Electrochem. Soc. $2000 ; 147: 4580$.

[17] A. M. Rao, P. C. Eklund, S. Bandow, A. Thess, R. E. Smalley, Evidence for charge transfer in doped carbon nanotube bundles from Raman scattering. Nature (London) 1997; 388: 257. 
[18] R. S. Lee, H. J. Kim, J. E. Fischer, A. Thess, R.E. Smalley, Conductivity enhancement in single-walled carbon nanotube bundles doped with $\mathrm{K}$ and $\mathrm{Br}$. Nature (London, U. K.) 1997; 388: 255.

[19] G. A. Snook, G. Z. Chen, Fray, D. J.; Hughes, M.; M. Shaffer, Studies of deposition of and charge storage in polypyrrole-chloride and polypyrrolecarbon nanotube composites with an electrochemical quartz crystal microbalance. J. Electroanal. Chem. 2004; 568: 135-142.

[20] S. Balaei, J. J. Aaron, A. Desbene-Monvernay, P.C. Lacaze, Ex situ and in situ fluorescence studies of electrosynthesized poly( $N$-vinylcarbazole) in the presence of various electrolytes. Synth. Met. 1992; 53: 95-107.

[21] Y. Sun, S. R. Wilson, D. I. Schuster, High Dissolution and Strong Light Emission of Carbon Nanotubes in Aromatic Amine Solvents. J. Am. Chem. Soc. 2001; $123:$ 5348-5349.

[22] M. Baibarac, I. Baltog, L. Mihut, N. Preda, T. Velula, C. Godon, J. Y. Mevellec, J. Wery, S. Lefrant, Surface enhanced Raman scattering and photoluminescence studies on single-walled carbon nanotubes submitted to nonhydrostatic compression. Journal of Optoelectronics and Advanced Materials $2005 ; 7: 2173-2180$.

[23] J. E. Riggs, Z. Guo, D. L. Carroll, Y. P. Sun, Strong Luminescence of Solubilized Carbon Nanotubes. J. Am. Chem. Soc. 2000; 122: 5879-5880.

[24] J. Pina, J. Seixas de Melo, H. D. Burrows, A. P. Monkman, S. Navaratnam, On the triplet state of poly( $N$-vinylcarbazole). Chem. Phys. Lett. 2004; 400: 441445. 
[25] N. Ballav, M. Biswas, A conducting composite of polyN-vinylcarbazole and polythiophene. Synth. Met. 2003; 132: 213-218.

[26] S. Quillard, G. Louarn, S. Lefrant, A.G. Macdiarmid, Vibrational analysis of polyaniline: A comparative study of leucoemeraldine, emeraldine, and pernigraniline bases. Phys. Rev. B 1994; 50:12496-12508.

[27] M. Baibarac, I. Baltog, S. Lefrant, J.Y. Mevellec, O. Chauvet, Polyaniline and Carbon Nanotubes Based Composites Containing Whole Units and Fragments of Nanotubes. Chem. Mater. 2003; 15: 4149-4156.

[28] M. Sacak, Electrochemical synthesis of poly( $N$-vinyl carbazole) doped with $\mathrm{HSO}_{4}{ }^{-}$and $\mathrm{NO}_{3}{ }^{-}$anions. J. Appl. Polym. Sci. 1999; 74:1792-1796.

[29] R. Saraswathi, M. Gerard, B. D. Malhotra, Characteristics of aqueous polycarbazole batteries. J. Appl. Polym. Sci. 1999; 74:145-150.

[30] M. S. Michael, S. R. S. Prabaharan, Rechargeable lithium battery employing a new ambient temperature hybrid polymer electrolyte based on PVK+PVdF-HFP (copolymer). J. Power Sources 2004; 136: 408-415.

[31] P. Gomez-Romero, Hybrid Organic-Inorganic Materials - In Search of Synergic Activity. Adv. Mater. 2001; 13: 163-174.

\section{Figure Caption}

Fig. 1 Voltammograms recorded on blank Pt electrode (a, the first 20 cycles) and coated with a SWNTs film (b, the first 100 cylces) immersed in the $\mathrm{CH}_{3} \mathrm{CN}+$ $\mathrm{LiClO}_{4}\left(10^{-1} \mathrm{M}\right)+\mathrm{NVK}\left(610^{-3} \mathrm{M}\right)$ solution; scan rate is equal with $100 \mathrm{mV} \mathrm{s}{ }^{-1}$.

Fig. 2 TEM micrographs of: a) SWNTs, b) MWNTs, $\mathbf{c}_{\mathbf{1 - 2}}$ ) PVK functionalised SWNTs and $\mathbf{d}_{\mathbf{1 - 2}}$ ) PVK functionalised MWNTs. 
Fig. 3 Ex situ fluorescence emission spectra $\left(\lambda_{\text {exc }}=265 \mathrm{~nm}\right)$ of the PVK deposited on the SWNTs film during of the 20 (curve 1), 50 (curve 2), 100 (curve 3) and 200 cycles (curve 4) carry out in the solution of $\mathrm{CH}_{3} \mathrm{CN}+\mathrm{LiClO}_{4}\left(10^{-1} \mathrm{M}\right)+\mathrm{NVK}$ $\left(610^{-3} \mathrm{M}\right)$. A identical curve 4 is also obtained when electrochemical process is carried out on the Pt electrode alone.

Fig. 4 ATR-IR spectra of PVK and PVK/SWNTs composites prepared by the achievement of 50 and 100 cycles (synthesis number 1 and 2, respectively) on the SWNTs film, immersed in a solution of $\mathrm{CH}_{3} \mathrm{CN}+\mathrm{LiClO}_{4}\left(10^{-1} \mathrm{M}\right)+\mathrm{NVK}\left(610^{-3} \mathrm{M}\right)$ in the potential range $(-0.8 ;+1.8) \mathrm{V}$ vs. $\mathrm{Ag} / \mathrm{Ag}^{+}$with a scan rate of $100 \mathrm{mV} \mathrm{s}^{-1}$.

Fig. 5 Influence of the monomer concentration on the electropolymerization reaction. Curves $\mathbf{c}_{1-\mathbf{V K}}, \mathbf{c}_{\mathbf{2}-\mathbf{V K}}$ and $\mathbf{c}_{\mathbf{3}-\mathbf{V K}}$ correspond to the $100^{\text {th }}$ cyclic voltammogram recorded on SWNTs film deposited on Pt electrode, using a solution of $10^{-1} \mathrm{M} \mathrm{LiClO}_{4}$ in $\mathrm{CH}_{3} \mathrm{CN}$ and $310^{-3}, 610^{-3}$ and $2.410^{-2} \mathrm{M} \mathrm{VK}$, respectively (a). Influence of the $\mathrm{LiClO}_{4}$ concentration used on cyclic voltammograms carry out on the Pt electrode coated with a SWNTs film in $610^{-3} \mathrm{M} \mathrm{VK}$ and $\mathbf{c}_{\text {1-LiClO4}}: 10^{-2} \mathrm{M}, \mathbf{c}_{2-\mathrm{LiClO4}}: 10^{-1} \mathrm{M}, \mathbf{c}_{3-}$ LiClO4: $210^{-1} \mathrm{M}$ and $\mathbf{c}_{4-\mathrm{LiClO4}}$ : $510^{-1} \mathrm{M} \mathrm{LiClO}_{4}$ in $\mathrm{CH}_{3} \mathrm{CN}$ at a scan rate of $100 \mathrm{mV} \mathrm{s}^{-1}$. In all figures is shown the $100^{\text {th }}$ cyclic voltammogram (b).

Fig. 6 Voltage profile for PVK-functionalized SWNTs and PVK-functionalized MWNTs. The insert shows incremental capacity curves for PVK-functionalized SWNTs and PVK-functionalized MWNTs (a). The effect of cycle life on PVK battery capacity (b).

Scheme 1 Mechanism of the electropolymerisation reaction of VK on the SWNTs film. 


\section{ACCEPTED MANUSCRIPT}

Scheme 2 Chemical equation of non-conducting PVK - functionalised SWNTs and conducting PVK - functionalised SWNTs. 
Chemical Stage

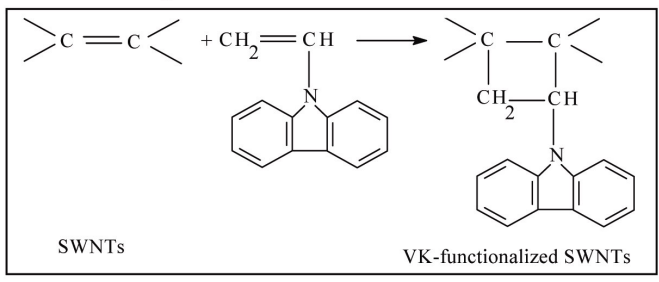

Electrochemical Stage

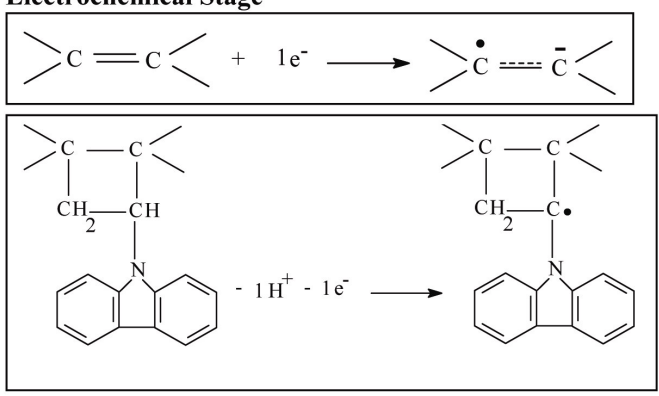

Chemical Stage
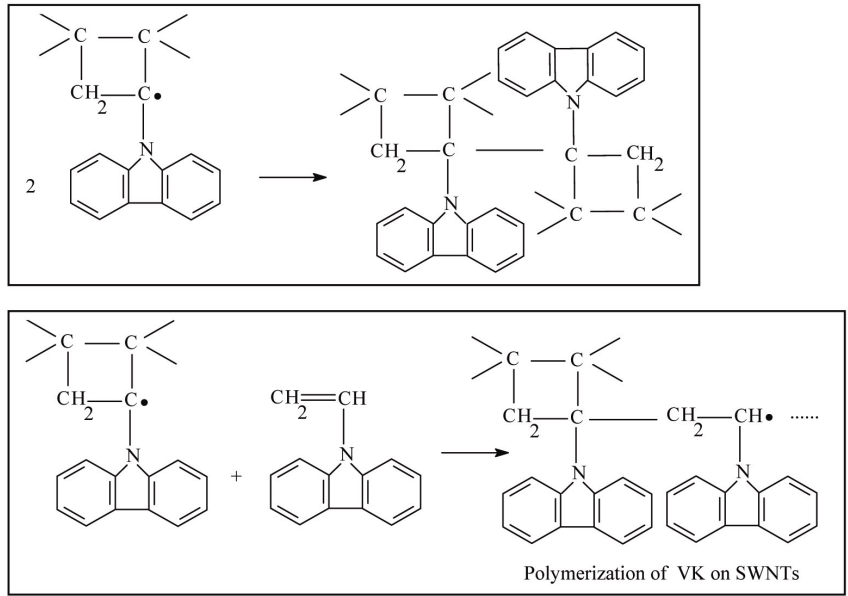

Scheme 1 

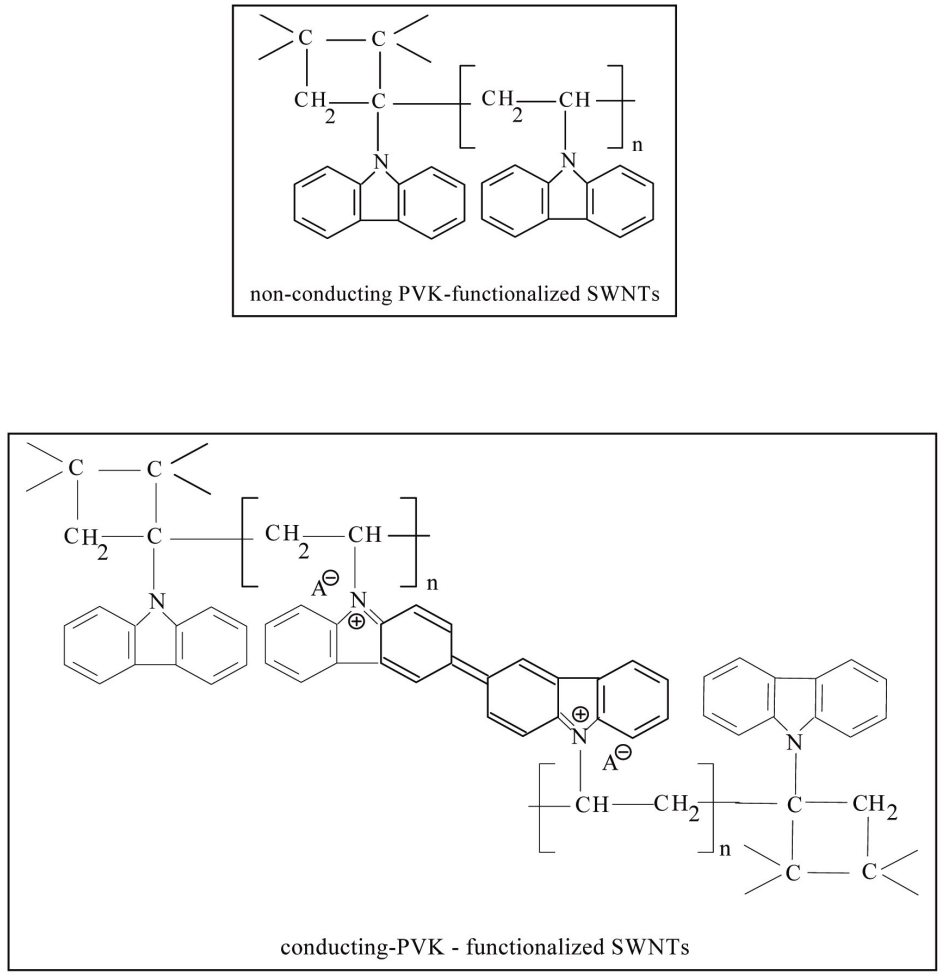

Scheme 2 


\section{ACCEPTED MANUSCRIPT}

a

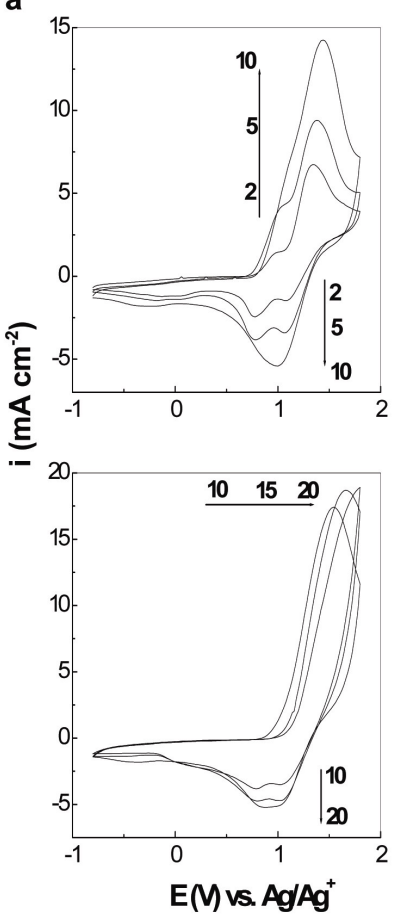

b
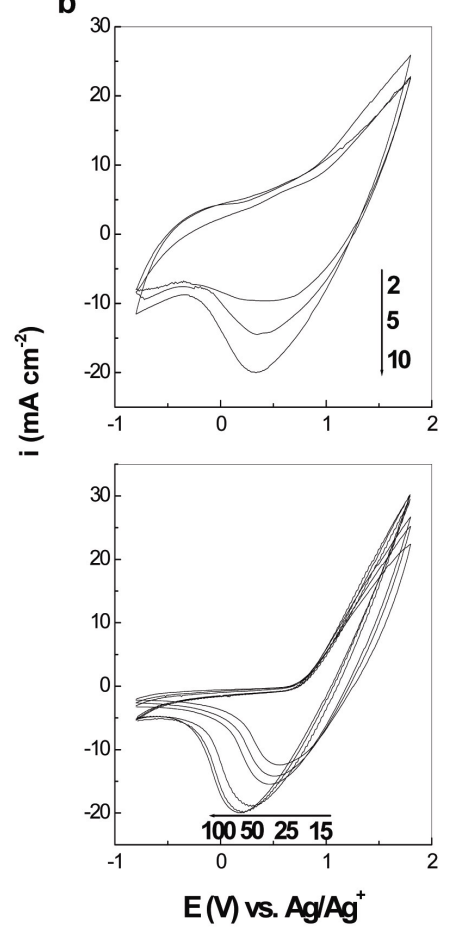

Fig.1 


\section{ACCEPTED MANUSCRIPT}

A)

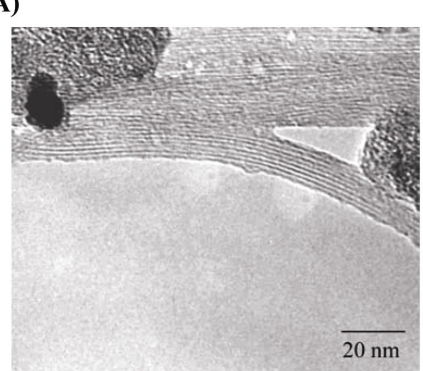

C)

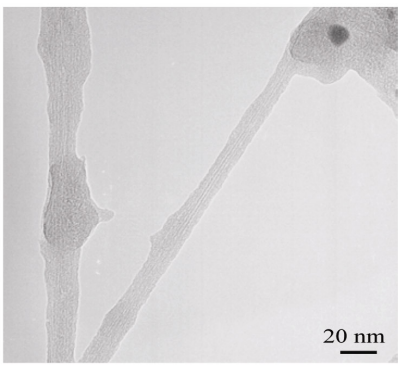

$\mathrm{C}_{2}$ )

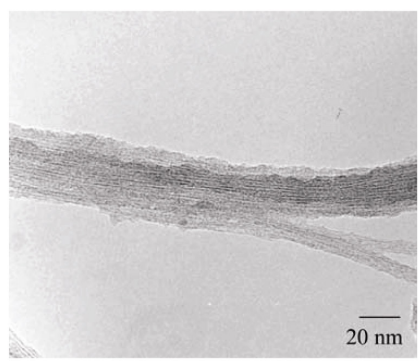

B)

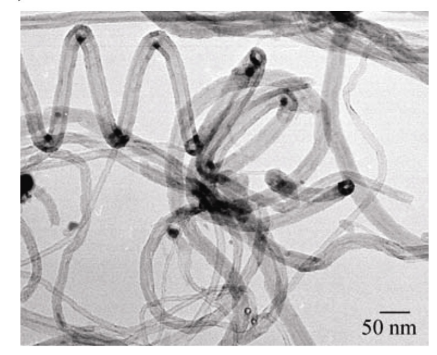

D)

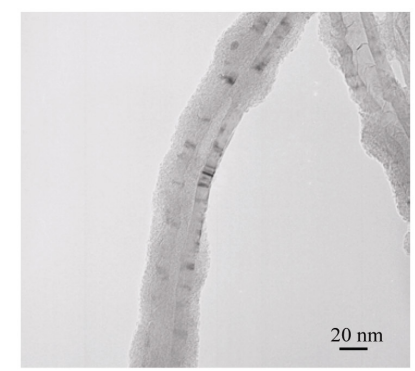

D)

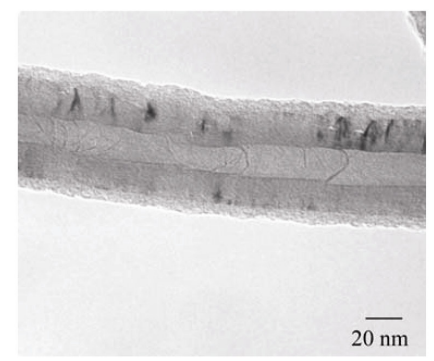

Fig.2 


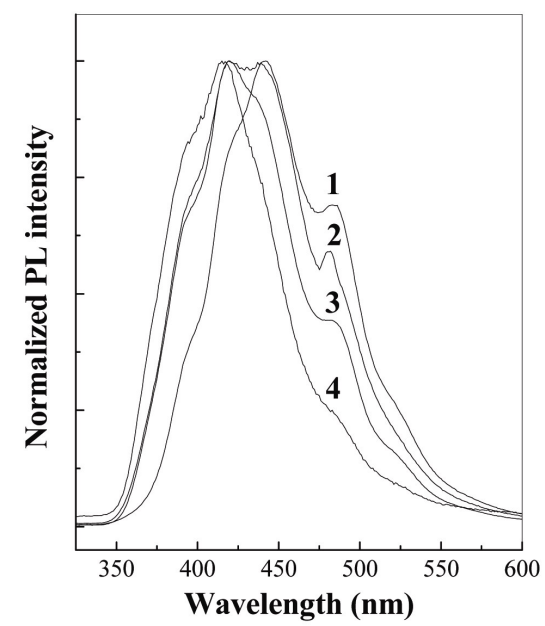

Fig.3 


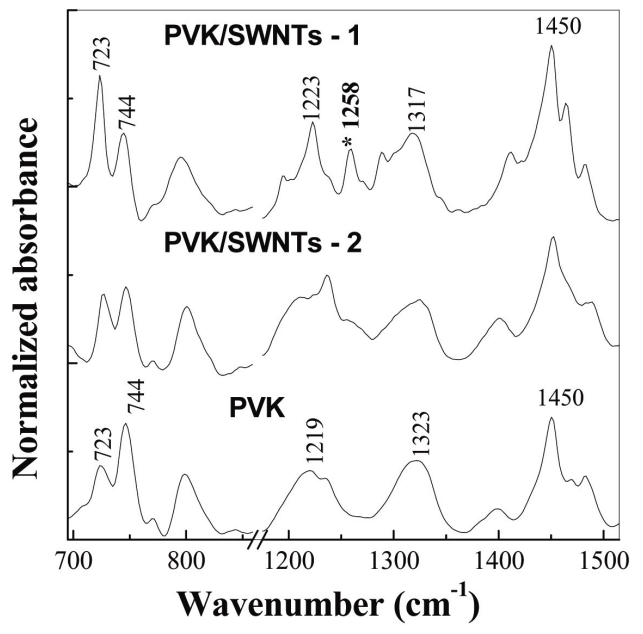

Fig.4 
a

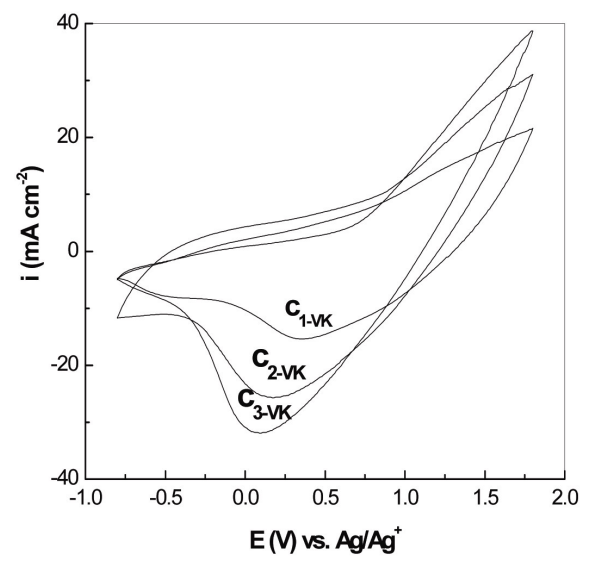

b

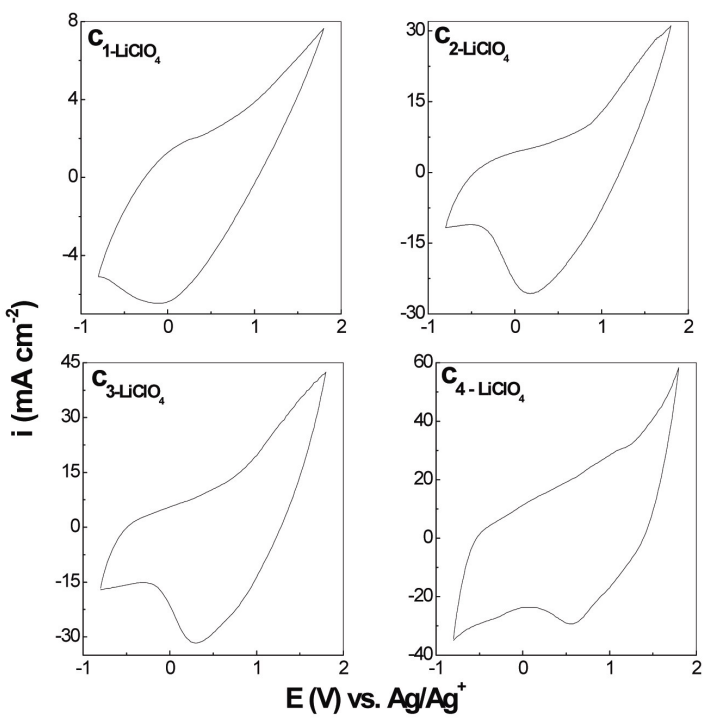

Fig.5 
a)

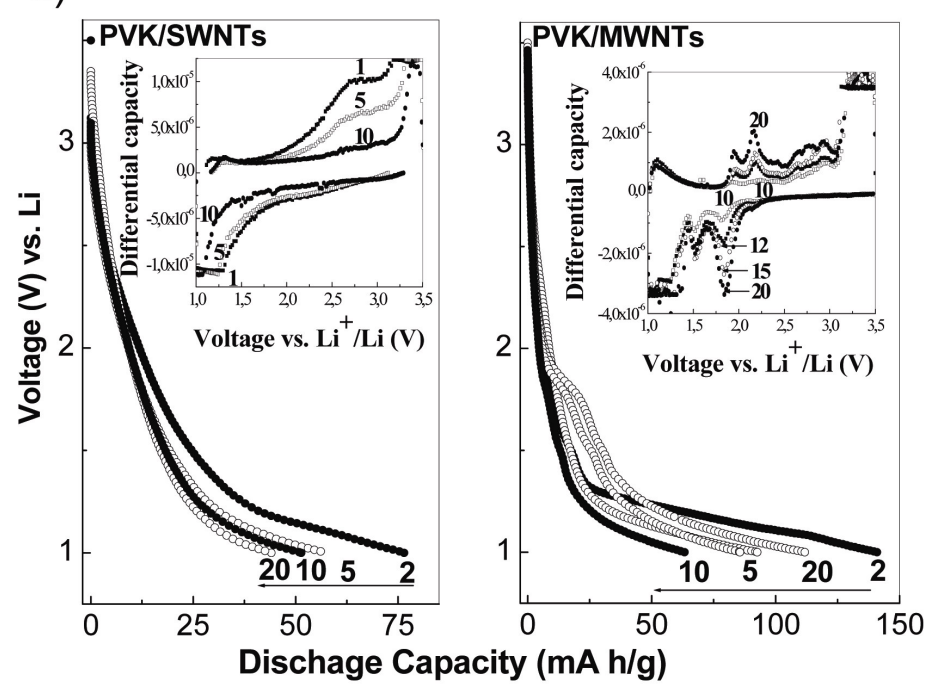

b)

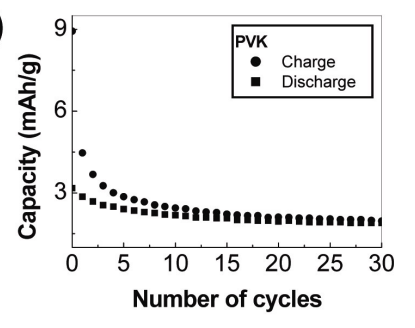

Fig.6 